\title{
Integrasi Pendidikan Biologi Dalam Konservasi Lembu Putih Taro Berbasis Kearifan Lokal
}

\section{Made Maduriana1*, I Wayan Gata ${ }^{2}$}

1,2 Jurusan Pendidikan Biologi, IKIP Saraswati, Tabanan, Indonesia

\section{ART ICLE INFO}

\section{Article history:}

Received September 12, 2021

Revised September 19, 2021

Accepted October 14, 2021

Available online October 25, 2021

Kata Kunci:

SWOT, Pendidikan Biologi,

Konservasi, Lembu Putih Taro,

Kearifan Lokal

Keywords:

SWOT, Biology Education,

Conservation, White Bull Taro, Local Wisdom

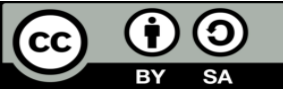

This is an open access article under the $\mathrm{CC}$ BY-SA license.

Copyright (C) 2021 by Author. Published by Universitas Pendidikan Ganesha.

\begin{abstract}
A B S T R A K
Penelitian ini merupakan penelitian lanjutan dari penelitian sebelumnya tentang lembu putih Taro sebagai konten dan media asli pembelajaran biologi. Pada penelitian ini peneliti berupaya mengungkap pentingnya integrasi pendidikan biologi dalam upaya konservasi lembu putih Taro dan kearifan lokal yang ada di dalamnya. Tujuan penelitian in adalah untuk memetakan pentingnya integrasi pendidikan sains biologi dalam mendukung upaya konservasi lembu putih Taro berbasis kearifan local budaya Hindu Bali berdasarkan analisis SWOT. Penelitian ini berupakan penelitian kualitatif. Data dikumpulkan dengan metode triangulasi data yaitu observasi, wawancara dan studi dokumen. Data dianalisis secara deskriptif kualitatif melalui analisis SWOT. Berdasarkan hasil analisis SWOT, dapat disimpulkan bahwa kelemahan dan ancaman upaya pelestarian lembu putih Taro berbasis kearifan local budaya Hindu Bali terletak pada pengelolaan sapi heterozigot karier yang dilahirkan oleh lembu putih Taro. Pembiaran ini secara genetika akan mengancam isolasi genetik lembu putih Taro. Pemahaman konsep biologi sangat penting, khususnya konsep genetika persilangan dalam memberikan pemahaman ilmiah kepada seluruh pihak yang terlibat dalam upaya konservasi lembu putih Taro berbasis kearifan lokal untuk mempertahankan isolasi genetiknya. Dukungan pemahaman konsep biologi dapat membantu konservasi genetis yang berkesinambungan pada konservasi lembu putih Taro berbasis kearifan lokal.
\end{abstract}

\begin{abstract}
A B S T RACT
This research is a continuation of previous research on the Taro white bull as the original content and media for biology learning. In this study, researchers seek to reveal the importance of integrating biology education in conserving the Taro white bull and its local wisdom. The purpose of this study was to map the importance of integrating biology science education in supporting the conservation of the Taro white bull based on local wisdom of Balinese Hindu culture based on a SWOT analysis. This research is qualitative. Data were collected by data triangulation method, namely observation, interview and document study. Data were analyzed descriptively qualitatively through SWOT analysis. Based on the SWOT analysis results, it can be concluded that the weakness and threat of preserving the Taro white bull based on local wisdom of Balinese Hindu culture lie in the management of carrier heterozygous cattle born to the Taro white bull. This genetic omission will threaten the genetic isolation of the Taro white bull. Understanding biological concepts is very important, especially the concept of cross genetics, in providing scientific understanding to all parties involved in conserving the Taro white bull based on local wisdom to maintain its genetic isolation. Based on local wisdom, support for understanding biological concepts can help sustainable genetic conservation in Taro white bull conservation.
\end{abstract}

\section{PENDAHULUAN}

Konservasi berbasis kearifan lokal dalam isolasi gen lebu putih Taro adalah sesuatu yang penting untuk masyarakat Desa Taro. Isolasi genetis lembu putih Taro menjadi salah satu penciri dari kearifan lokal di daerah tersebut. Kepercayaan masyarakat, mitos, adat istiadat, mitos, dan nilai konservasi alam menyatu dalam kearifan lokal di Desa Taro. Model konservasi berbasis kearifan lokal merupakan bagian dari etnoekologi (Candraningsih et al., 2018; Ilhami et al., 2021; Pauli et al., 2016), yang tidak lepas dari masyarakat Desa Taro. Konservasi lebu putih Taro dari aspek etnoekologi antara lain cosmos, praxis, dan corpus (Albuquerqu et al., 2019). Apsek cosmos konservasi lembu putih Taro sangat kuat secara lokal dengan panggilan "ida" atau "duwe" pada lembu putih menunjukkan rasa hormat masyarakat terhadap lembu putih Taro. Selain itu, mitos dan sugesti lembu putih Taro sebagai penyembuh beberapa jenis penyakit sudah dikenal di Bali, berdasarkan hasil wawancara ada beberapa anggota masyarakat yang telah membuktikan kebenaranya. Pada aspek praxis konservasi lembu putih Taro mendorong konservasi hutan, dan implementasi pertanian organik. Sedangkan pada aspek corpus, telah diteliti bahwa lembu putih Taro merupakan jenis lembu albino yang mengalami titik mutasi pada gen TRY (Putra, 2019). 
Perkawinan homozigot pada lembu putih Taro mestinya menghasilkan lembu putih yang sama. Namun, kenyataannya muncul beberapa lembu yang warna bulunya tidak putih, yang artinya ada persilangan pada gen heterozigot. Sehingga, hal tersebut dapat mengancam eksistensi lembu putih Taro ke depanya. Konservasi lembu putih Taro tidak cukup hanya dengan mengandalkan kearfian lokal yang berangkat dari mitos-mitos dan kepercayaan tradisional. Sangat penting semua pihak terkait memiliki pemahaman konsep biologi khususnya memastikan isolasi genetis untuk menjaga eksistensi lembu putih tersebut, selain kearifan lokal dalam upaya konservasinya.

Di Bali banyak kearifan lokal mendorong dilakukan konservasi lingkungan yang menarik dikaji dalam etnoekologi. Kearifan lokal tersebut berupa seperangkat mitos-mitos dan kepercayaan tradisional yang merupakan bagian integral dari system kepercayaan agama Hindu juga terbukti memberikan dampak positif terhadap kelestarian sistem ekologi. Contohnya adalah di Alas Kedaton Desa Kukuh, Sangeh di Gianyar, dan tempat-tempat suci lainnya yang masih banyak lagi di Bali. Berkaitan dengan itu mereka pantang mengganggu keberadaan berbagai jenis flora, fauna, dan sumberdaya lainnya yang ada di sekitar kawasan hutan. Pantangan ini berlandaskan kepercayaan bahwa para dewa akan selalu mengawasi dan memberikan ganjaran dan hukuman kepada setiap orang yang berani mengganggu kawasan tersebut (Sudirgayasa et al., 2021). Demikian pula dengan keberadaan satwa lembu putih di Desa Taro, Kecamatan Tegallalang, Kabupaten Gianyar, Bali. Dalam konsepsi keyakinan masyarakat Desa Taro, lembu putih dipandang sebagai binatang suci milik dewa-dewa yang melindungi kehidupan mereka. Oleh karenanya keberadaannya sangat dihormati dan mereka menyebut satwa lembu putih sebagai lembu duwe atau lembu milik Dewa (Heryani et al., 2018). Adanya kepercayaan semacam itu menutup kemungkinan bagi penduduk untuk memperoleh manfaat-manfaat nyata secara langsung. Hal tersebut tidak terlepas dari adanya pantangan bagi pemanfaatan binatang suci tersebut untuk kepentingan duniawi, seperti pantangan untuk menyembelih atau mengkonsumsi daging maupun susunya, pantang mempekerjakannya dalam aktivitas-aktivitas pertanian maupun sebagai sarana transportasi atau keperluan lainnya.

Penelitian tentang sapi Taro sudah banyak dilakukan misalnya potensi sebagai media asli dan konten pembelajaran biologi (Sudirgayasa et al., 2021), profil sekuen mutasi gen tyrosinase (Sudirgayasa et al., 2021), karakteristik morfometrik (Depison et al., 2020; Heryani et al., 2018), dan dukungan pakan (Suarna et al., 1970). Namun belum ada yang menggali usaha konservasi melalui pemahaman isolasi genetis. Pemahaman isolasi genetis ini sangat penting untuk mempertahankan eksistensi sapi putih taro dengan gen yang homozigot agar kelestariannya tetap terjaga. Kegiatan konservasi berbasis kearifan lokal yang kuat mestinya didasari dengan pemahaman biologi terkait dengan bagaimana spesies dapat tetap eksis dalam ekosistemnya (Albuquerqu et al., 2019; Roué, 2020). Kekuatan dari cosmos dan praxis dalam bentuk mitos-mitos dan berbagai ritual yang berkaitan dengan pemanfaatan lembu putih Taro cukup kuat dalam usaha konservasinya. Namun, perlu diperkuat lagi dengan aspek corpus, dimana dalam usaha konservasi bagaimana proses penyilangan,mempertahankan isolasi genetis sangat perlu dipahami oleh pengelola dan masyarakat setempat yang berperan aktif dalam usaha konservatif ini. Artikel ini membahas tentang pentingnya pemahaman persilangan dan proses isolasi genetis sebagai bagian dari ilmu biologi khususnya genetika dalam konservasi sapi Taro. Pengetahuan sains biologi mendukung konservasi melalui kesadaran terhadap kelemahan dan ancaman upaya pelestraian tersebut dan meminimalisirnya melalui upaya isolasi genetis. Pertanyaan inilah yang melatar belakangi penulis untuk mengakaji lebih lanjut melalui penelitian lanjutan ini. Harapannya aka diperoleh gambaran hubungan keterkaitan antara nilai-nilai kearifan lokal dari suatu mitos dan kepercayaan masyarakat dengan integrasi pengetahuan sains biologi dalam hal pelestarian alam beserta isinya.

\section{METODE}

Untuk mencapai tujuan penelitian tersebut, metode yang tim penulis gunakan adalah metode penelitian deskriptif eksploratif yang berusaha mendeskripsikan suatu gejala atau peristiwa secara mendetail (Jackson, S.L., 2009: 15). Subjek penelitian ini adalah pengelola konservasi lembu Taro. Data diperoleh dari proses observasi, wawancara, dan studi dokumen terkait konservasi sapi Taro berbasis kearifan lokal. Untuk menjamin data yang bervariasi dan komprehensif dilakukan triangulasi sumber data. Pengumpulan data dilakukan melalui observasi, wawancara dan studi dokumen. Pertama observasi, setelah pembagian tugas, masing-masing tim peneliti melakukan observasi di kawasan Ekowisata Lembu Putih Desa Taro. Observasi yang dilakukan di sini adalah observasi naturalistik yaitu penelitian yang dilakukan dalam konteks atau seting lingkungan yang sesungguhnya (Marczyk, DeMatteo, \& Festinger, 2005: 149). Kedua wawancara, wawancara yang dilakukan adalah wawancara terstruktur. Ketiga studi dokumen, yang dilakukan dengan mengkaji dokumen-dokumen terkait Ekowisata Lembu putih Desa Taro. Dokumen yang digunakan adalah buku, jurnal-jurnal hasil penelitian 
terkait dan lampiran peraturan menteri pendidikan dan kebudayaan nomor 67, 68,69, dan 70 tahun 2013 tentang kerangka dasar dan struktur kurikulum SD, SMP, SMA dan SMK. Seluruh teknik pengumpulan data diarahkan untuk memetakan dalam keperluan analisis SWOT. Data analisis SWOT yang telah terkumpul nantinya dijabarkan dan dibahas secara deskriptif kualitatif. Penyajian data dilakukan dengan mendeskripsikan seluruh temuan yang dilengkapi dengan tabel dan gambar. Dengan demikian akan terlihat gambaran secara rinci khususnya tentang kelemahan dan ancaman yang perlu dukungan pengetahuan sains biologi.

\section{HASIL DAN PEMBAHASAN}

Hasil

Berdasarkan hasil pengumpulan triangulasi data yang telah dilakukan berbasis SWOT, maka dapat dirangkum pada Tabel 1.

Tabel 1. Hasil Analisis SWOT Konservasi Lembu Putih Taro Berbasis Kearifan Lokal

\begin{tabular}{cl}
\hline Aspek & \multicolumn{1}{c}{ Hasil Analisis } \\
\hline Strengths/kekuatan & Adanya perlakuan khusus terhadap lembu putih Desa Taro dilatarbelakangi \\
& oleh mitos tentang lembu putih sebagai binatang suci milik para dewa. Di \\
& balik mitos tersebut terdapat kearifan-kearifan sebagai bentuk respon \\
& adaptasi manusia terhadap kondisi-kondisi lingkungan yang dihadapinya. \\
& Berdasarkan hasiol observasi dan wawancara, serta studi beberapa artikel \\
& misalnya artikel Pujaastawa, I.B.G. dan Suwena, IW, (2013), diperoleh \\
& kekuatan atau keunggu lan pengelolaan ekowisata lembu putih Desa Taro \\
& sebagai berikut.
\end{tabular}

1) Lahirnya kebijakan distribusi lahan pertanian dan upah

Pemeliharaan kawasan ekowisata lembu putih dilakukan dengan dibentuknya kelompok pengangon atau kelompok pemelihara lembu putih yang melibatkan sejumlah warga desa adat setempat. Tugas dan kewajiban masing-masing pengangon antara lain menyediakan pasokan makanan, memandikan lembu, dan membersihkan kandang. Sebagai imbalan atas tugas dan kewajiban yang dipikulnya, maka kepada masing-masing pengangon oleh pihak desa adat diberikan sebidang lahan pertanian berupa tegalan dengan luas berkisar antara 8 hingga 12 are, dengan status sebagai penyakap. Berbeda dengan hak dan kewajiban para penyakap lahan konversi sebelumnya, para pengangon berhak sepenuhnya atas hasil-hasil tegal yang disakapnya tanpa dikenakan kewajiban membayar iuran. Ha1 ini di samping diperhitungkan sebagai kompensasi atas tugas dan kewajiban yang diberikan kepadanya, juga karena lahan yang disakap oleh masingmasing pengangon dianggap relatif sempit. Pemberian hak dan kewajiban sebagai pengangon diprioritaskan kepada mereka yang tidak memiliki lahan garapan atau pemilik lahan garapan yang relative sempit. Meskipun luas tegal yang mereka sakap relative sempit, namun para pengangonumumnya menganggap sangat berarti untuk memenuhi kebutuhan keluarganya.

2) Secara langsung sebagai system pengendalian hama Pada mulanya ketika usaha tani di atas lahan konversi mulai dicoba, populasi lembu putih yang tinggal hanya tiga ekor tidaklah dipandang sebagai ancaman yang serius bagi keberhasilan usaha tani penduduk. Namun, dalam perkembangan lebih lanjut tidak dapat dipungkiri bahwa meningkatnya populasi lembuputih mulai menimbulkan kerugian yang cukup berarti bagi usaha tani penduduk. Namun dengan adanya tindakan konservasi untuk melin-dungi keberadaan lembu putih melalui pemeliharaan intensif dengan sistem kereman mengakibatkan sangat terbatasnya ruang gerak satwa tersebut. Hal tersebut secara tidak langsung merupakan suatu mekanisme pengendalian hama yang cukup efektif. 


\begin{tabular}{ll}
\hline Aspek & \multicolumn{1}{c}{ Hasil Analisis } \\
\hline 3) & Salah satu bentuk pemurnian genetika \\
& Sejak lembu putih dipelihara secara intensif dengan pemagaran di \\
& sekeliling kandang, menyebabkan kecil kemungkinan terjadinya kontak \\
& seksual antara lembu putih dengan ternak sapi peliharaan penduduk. \\
& Kontak seksual terbatas hanya dengan sesama jenis (perkawinan \\
& intraje-nis) baik pada lembu putih maupun ternak sapi peliharaan \\
& penduduk. Hal tersebut menyebabkan kemurnian sifat-sifat turunan \\
& dari masing-masing jenis akan lebih terjamin.
\end{tabular}

4) Diyakini mampu menyembuhkan penyakit.

Sapi albino Desa Taro yang disucikan terbukti mampu menyembuhkan berbagai penyakit. Berdasarkan penuturan pengelola, seluruh hasil ekskresi, susu, dan buangan pencernaan dapat digunakan untuk menyembuhkan berbagai penyakit. Tentunya hal ini didukung dengan keyakinan dan ritual keagamaan tertentu. Keyakinan ini sekali lagi sebagai penguat bahwa keberadaan lembu putih Desa Taro merupakan anugerah yang patut dijaga kelestariannya.

5) Digunakan dalam upacara keagamaan

Binatang dalam agama Hindu sangat banyak dimanfaatkan sebagai binatang suci atau pun binatang yang dijadikan kurban dalam pelaksanaan yadnya. Binatang dalam peranannya untuk caru telah dijumpai sejak jaman prasejarah sampai sekarang ini. Mapepada adalah upacara yang bertujuan untuk memberikan jalan kelepasan atau menyupat (nyomya) binatangbinatang yang digunakan sebagai korban dalam upacara Bhuta Yadnya agar nantinya roh binatang tersebut kalau berinkarnasi kembali ke dunia bisa lahir menjadi manusia (Partama, 2015).

Upacara mapepada yang di laksanakan di Pura agung Gunung raung menggunakan binatang lembu putih yang disakralkan oleh masyarakat desa taro. Selain lembu putih, ada juga binatang yang lain, seperti kerbau, kambing, kijang, anjing (asu bangbungkem), ayam, bebek, penyu, babi, angsa, dan lain lainnya. Lembu putih yang digunakan dalam upacara mapepada tersebut adalah lembu putih jantan yang masih muda (pedet/godel). Lembu putih tersebut dibusanai (diberi pakaian) dengan kain berwarna putih dan diberi kalung uang kepeng. seperti halnya binatang-binatang yang lain, lembu putih ini juga diarak mengelilingi Pura agung Gunung raung (memurwa daksina) sebanyak tiga kali dari arah timur ke selatan. setelah upacara mapepada, lembu putih dan binatang-binatang yang lainnya selanjutnya dipotong untuk pelengkap upakara Tawur Panca Wali Krama agung. Mamurwa daksina ini melambangkan upacara menuju kesucian. Berputar tiga kali mengelilingi Pura agung Gunung raung merupakan lambang menuju tuhan. Dengan demikian, keberadaan lembu putih ini harus selalu ada. Ditambah dengan adanya keyakinan penyucian dan disakralkan maka peluang untuk keberlangsungan hidup lembu putih tersebut sangat besar

Weakness/kelemahan Berdasarkan hasil observasi, wawancara dan studi dokumen terkait. Kami temukan beberapa kelemahan pengelolaan ekowisata lembu putih Desa Taro sebagai berikut.

1) Ikuti disucikannya sapi heterozigot karier

Sapi heterozigot karier merupakan sapi dengan fenotif sama dengan sapi Bali pada umumnya yang lahir dari indukan albino yang disucikan

2) Minimnya luas kawasan ekowisata

Luasan lahan konservasi hanya 8,925 ha. Sangat kurang sebagai daya dukung pakan. Sehingga diperlukan usaha untuk mendapatkan sumber pakan dari luar. Ditambah dengan system pengandangan atau penangkaran. Sehingga sangat tergantung dengan penyediaan bahan pakan dari pengelola. 


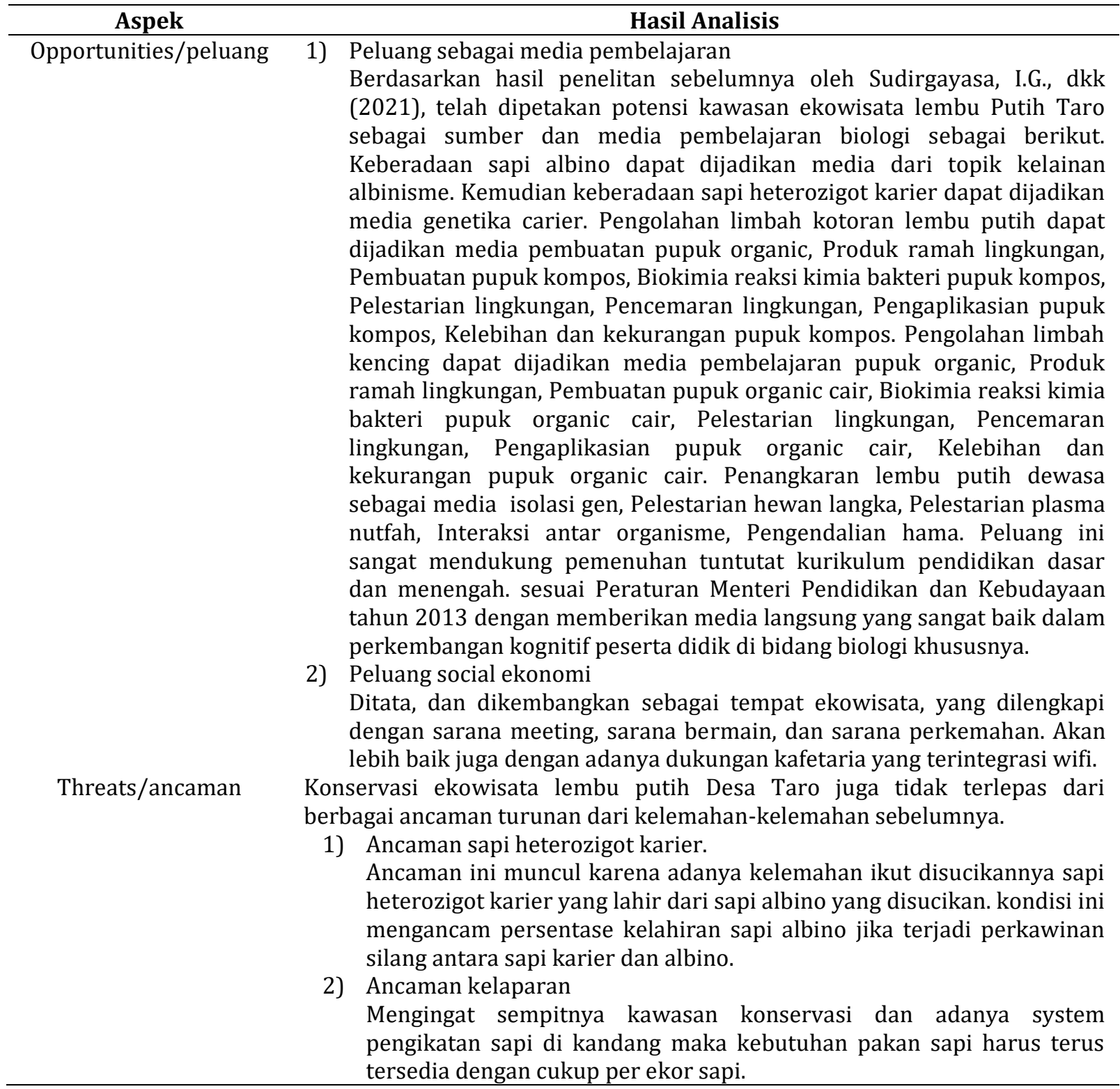

\section{Pembahasan}

Fokus utama analisis SWOT yang telah dipetakan adalah pada faktor kelemahan dan ancaman konservasi lembu putih Desa Taro berbasis kearifan lokal budaya. Konservasi model ini memang memiliki berbagai kekuatan dan peluang yang luas. Namun demikian, adanya kesadaran ancaman dicampurkannya sapi karier heterozigot justru luput dari pantauan. Dari sini kita dapat pahami bahwa pengetahuan dasar biologi khususnya genetika harus dipahami oleh seluruh pemangku kepentingan terkait. Berdasarkan persilangan genetika, perkawinan antara sapi dengan berbagai genotif akan menghasilkan persentase keturunan yang berbeda seperti yang tampak pada Gambar 1. Gambar 1 menunjukkan bahwa persentase terbesar kelahiran sapi albino diperoleh dari perkawian indukan yang seluruhnya albino. Selain itu akan mengurangi peluang lahirnya sapi albino dan bahkan menghilangkan peluang lahirnya sapi albino. Berkurangnya persentase kelahiran sapi albino merupakan ancaman nyata jangka panjang dalam upaya pelestariannya. Di sinilah pentingnya integrasi pendidikan sains biologi sebagai salah satu faktor penting upaya pelestarian lembu putih Desa taro. Pemahaman genetika persilangan sebagai bagian dari praxis etnoekologi (Albuquerqu et al., 2019; Pauli et al., 2016) lembu putih Taro penunjang implementasi isolasi genetis dari lembu putih Taro tersebut.

Pemahaman sains biologi ini perlu diupayakan oleh pengelola agar seluruh yang terlibat paling tidak memiliki kesadaran akan kelemahan dan ancaman pengelolaan yang telah dijabarkan sebelumnya. Penanaman pemahaman ini dapat dilakukan dengan berbagai cara. Misalnya melalui peningkatan kompetensi pengelola yang sudah ada melalui seminar, penyuluhan, lokakarya, pelatihan dan sejenisnya. 
Atau dapat juga dilakukan dengan merekrut pengelola dengan kompetensi sains biologi yang memadai. Dengan demikian, akan diperoleh hasil yang lebih optimal dan berkelanjutan. Itu artinya, selain kita berperan dalam menjaga kelestarian suatu makhluk hidup, kita juga turut mengamalkan ajaran agama dan warisan kearifan lokal budaya kita (Indrawan et al., 2020; Suastra et al., 2017; Suja, 2017; Sutajaya, 2020). Oleh karena itu, peran kita sebagai generasi muda yang melek sains sangat dibutuhkan oleh masyarakat. Teori yang kita peroleh di bangku sekolah sudah saatnya kita terapkan mulai dari lingkungan masyarakat sekitar moto think globaly act locally (Sutajaya, 2020; Torre et al., 2021; Watanabe, 2018).

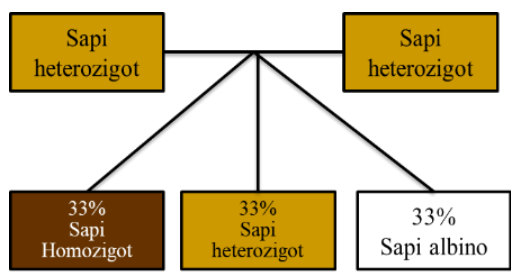

a. persilangan heterozigot dan heterozigot

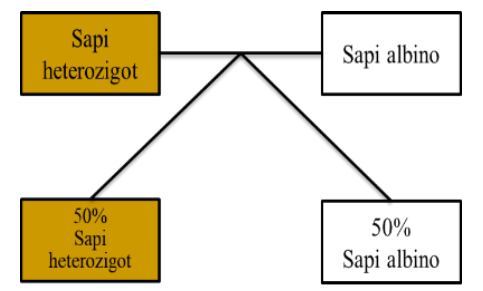

b. persilangan heterozigot dan homozigot

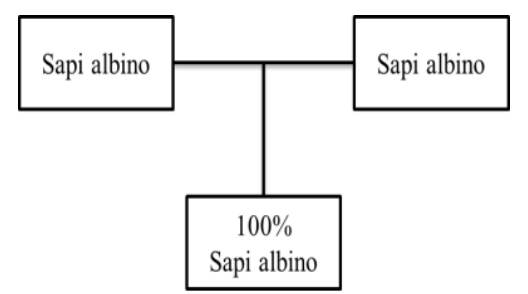

c. persilangan homozigot dan homozigot

Gambar 1. Perbandingan prentase keturunan perkawinan berbagai genotof dan fenotif sapi

Penelitian sapi Taro telah dilakuan sejak lama oleh para peneliti ditinjau dari aspek corpus misalnya penelitian terkait profil sekuen mutasi gen tyrosinase (Putra, 2019), karakteristik morfometrik (Depison et al., 2020; Heryani et al., 2018), dan dukungan pakan (Suarna et al., 1970). Praxis integrasi kearifan lokal dari konsevasi lembu putih Taro dalam pembelajaran (Sudirgayasa et al., 2021). Selain itu, integrasi kearifan lokal sudah banyak diintegrasikan ke dalam pembelajaran baik dalam bentuk konten, konteks, maupun model (Gunawan, 2019; Khoiri, 2018; Kurniawan, 2021; Risdianto, 2021; Sarwi, 2020; Sudarmin, 2020), belum ada penelitian yang membawa pendidikan dan pembelajaran ke dalam kearifan lokal untuk mendukung upaya konservasi yang ada di dalamnya. Belum ada penelitian konsep biologi pola persilangan untuk masyarakat memahami bagaimana cara mengisolasi gen lembu putih Taro agar tetap homozigot. Penelitian ini selain melakukan analisis SWOT terhadap konservasi berbasis kearifan lokal pada lembu putih Taro tetapi juga memberikan gambaran persilangan sapi Taro untuk menghasilkan keturunan homozigot atau heterozigot yang penting dipahami oleh pengelola tempat konservasi. Pengetahuan ini diharapkan menjadi dasar implementasi persilangan lembu putih Taro, dengan pertimbangan isolasi genetisnya, agar lembu putih Taro tetap lestari.

Integrasi pendidikan biologi dalam konservasi berbasis kearifan lokal akan memperkuat pemahaman ilmiah yang mendukung kearifan lokal secara etnosains (Hikmawati, 2021; Pauli et al., 2016), khususnya etnoekologi dalam penelitian ini. Keadaan spesies tertentu yang menjadi kajian dalam kearifan lokal dapat dikaji dari berbagai aspek keilmiahan secara biologi misalnya taksonomi, genetika, dan ekologi (Albuquerqu et al., 2019; Voeks, 2018). Pemahaman biologi meningkatkan kecintaan dan keyakinan berdasarkan kearifan lokal yang dimiliki, karena adanya dukungan nilai ilmiah (Atmojo, 2019; Mourão et al., 2018; Syakur, 2021; Voeks, R.S., 2018). Dukungan konsep-konsep ilmiah biologi memperkuat kedayatahanan kearifan lokal terhadap perkembangan jaman dan teknologi. Selain itu, biologi mengekslorasi lebih dalam makna filosofi dan alasan di balik kearifan lokal yang baik tersebut layak untuk dipertahankan (Sturtevant, 2017; Sutajaya, 2020). Integrasi pendidikan biologi dalam konservasi lembu putih Taro sangat penting sebagai aspek corpus yang dalam hal ini mendukung secara praktik persilangan yang mampu menjaga isolasi genetis. Implikasi penelitian ini dorongan kepada pihak-pihak terkait untuk melakukan pelatihan, sosialisasi, atau praktek terkait persilangan lembu putih Taro untuk mendukung isolasi genetis dan membantu pengembangan persilangan yang aman untuk mempertahankan kelestasrian lembu putih Taro dan kearifan lokal di Desa taro.

\section{SIMPULAN}

Artikel ini memaparkan hasil analisis SWOT konservasi lembu putih Taro berbasis kearifan lokal dan solusi terhadap kelemahan dan tantangannya melalui integrasi pendidikan biologi terkait pola persilangan untuk mempertahankan isolasi genetis/menghasilkan turunan yang bersifat homozigot. Penelitian selanjutnya dapat merancang pola konservasi lembu putih taro berdasarkan isolasi genetis yang lebih efektif untuk meningkatkan secara kualitas dan kuantitas yang tidak tidak melanggar kearifan lokal yang berlaku. 


\section{DAFTAR PUSTAKA}

Albuquerqu, U. P., Lucena, R. F. P. de, \& Cunha, L. V. F. C. (2019). Methods and Techniques in Ethnobiology and Ethnoecology (2nd ed.) (Second Edi, Issue January). Humana Press.

Atmojo, S. E. (2019). Science Learning Integrated Ethnoscience to Increase Scientific Literacy and Scientific Character. In Journal of Physics: Conference Series (Vol. 1254, Issue 1). https://doi.org/10.1088/1742-6596/1254/1/012033.

Candraningsih, I. A. K., Pujaastawa, I. B. G., \& Sudiarna, I. G. P. (2018). Konservasi Hutan Berbasis Kearifan Lokal di Desa Tigawasa, Kecamatan Banjar, Kabupaten Buleleng. Humanis, 22, 35. https://doi.org/10.24843/jh.2018.v22.i02.p06.

Depison, D., Crisdayanti, S., Gushairiyanto, G., \& Erina, S. (2020). Identifikasi Karakteristik Morfometrik Sapi Bali dan Sapi Brahman Cross di Kecamatan Pamenang Barat Kabupaten Merangin. Jurnal Peternakan Sriwijaya, 9(2), 11-20. https://doi.org/10.33230/jps.9.2.2020.11945.

Gunawan, Y. Y. (2019). The analysis of students' critical thinking skill through ethnoscience instruction integrated on the topic of magnetic field. In AIP Conference Proceedings (Vol. 2194). https://doi.org/10.1063/1.5139765.

Heryani, L. G. S., Susari, N. N. W., \& Gunawan, I. W. N. F. (2018). Variabel Komponen Utama Pada Morfometrik Sapi Putih Taro Berdasarkan Pengukuran Badan. Buletin Veteriner Udayana, February, 93. https://doi.org/10.24843/bulvet.2018.v10.i01.p15.

Hikmawati. (2021). Local wisdom in Lombok island with the potential of ethnoscience for the development of learning models in junior high school. In Journal of Physics: Conference Series (Vol. 1816, Issue 1). https://doi.org/10.1088/1742-6596/1816/1/012105.

Ilhami, A., Suci, D. A., Fernando, A., \& Pernantah, P. S. (2021). Ethnoecology Local Communities on Kasboyo Lake : Exploration of Conservation Values Using the Ethnoscience Approach as a Source of Natural Science Learning. Indonesian Journal of Integrated Science Education, 3(2), 149-156.

Indrawan, I. P. O., Sudirgayasa, I. G., \& ... (2020). Integrasi Kearifan Lokal Bali di Dunia Pendidikan. Prosiding Webinar ..., 3, 189-194.

Khoiri, A. (2018). Ethnoscience Approach in Cooperative Academic Education Programs (COOP). In Journal of Physics: Conference Series (Vol. 1114, Issue 1). https://doi.org/10.1088/1742$6596 / 1114 / 1 / 012018$

Kurniawan, R. (2021). The validity of e-module based on guided inquiry integrated ethnoscience in high school physics learning to improve students' critical thinking. In Journal of Physics: Conference Series (Vol. 1876, Issue 1). https://doi.org/10.1088/1742-6596/1876/1/012067.

Mourão, S., Luiz, M., \& Barbosa, V. (2018). Ethnotaxomy as a Methodological Tool for Studies of the Ichthyofauna and Its Conservation Implications : A Review. In Ethnozoology (Animals in Our Lives) (Issue 1974). Elsevier Inc. https://doi.org/10.1016/B978-0-12-809913-1.00006-5.

Pauli, N., Abbott, L. K., Negrete-Yankelevich, S., \& Andrés, P. (2016). Farmers' knowledge and use of soil fauna in agriculture: A worldwide review. Ecology and Society, 21(3). https://doi.org/10.5751/ES08597-210319.

Putra, W. P. B. (2019). Profil Sekuen Gen Tyrosinase Pada Sapi Dan Kerbau Albino. 10(August).

Risdianto, E. (2021). Analysis of student responses toward ethnoscience based Direct Instruction learning model in learning physics applying Rasch Model Approach. In Journal of Physics: Conference Series (Vol. 1731, Issue 1). https://doi.org/10.1088/1742-6596/1731/1/012081.

Roué, M. (2020). A Tribute to Claudine Friedberg: Ethnoscience, taxonomies and interdisciplinarity. In Natures Sciences Societes (Vol. 27). https://doi.org/10.1051/nss/2020012.

Sarwi. (2020). The analysis of ethnoscience-based science literacy and character development using guided inquiry model. In Journal of Physics: Conference Series (Vol. 1567, Issue 2). https://doi.org/10.1088/1742-6596/1567/2/022045.

Sturtevant, W. C. (2017). Studies in ethnoscience. In Anthropological Theory: A Sourcebook (pp. 475-500). https://doi.org/10.4324/9781315082271_46.

Suarna, I. W., Duarsa, M. A. P., Mariani, N. P., Sumardani, L. G., \& Lindawati, S. A. (1970). Daya Dukung Hijauan Pakan Dalam Konservasi Sapi Putih Taro. Bumi Lestari Journal of Environment, 16(1), 3843. https://doi.org/10.24843/blje.2016.v16.i01.p06.

Suastra, I. W., Jatmiko, B., Ristiati, N. P., \& Yasmini, L. P. B. (2017). Developing characters based on local wisdom of bali in teaching physics in senior high school. Jurnal Pendidikan IPA Indonesia, 6(2), 306-312. https://doi.org/10.15294/jpii.v6i2.10681.

Sudarmin. (2020). Students' innovative and creative thinking skill profile in designing chemical batik after experiencing ethnoscience integrated science technology engineering mathematic integrated 
ethnoscience (ethno-stem) learnings. In Journal of Physics: Conference Series (Vol. 1567, Issue 2). https://doi.org/10.1088/1742-6596/1567/2/022037.

Sudirgayasa, I. G., Surata, I. K., Sudiana, I. M., Maduriana, I. M., \& Gata, I. W. (2021). Potensi Ekowisata Lembu Putih Taro Sebagai Konten dan Media Pembelajaran Biologi Berbasis Kearifan Lokal Hindu Bali. Jurnal Imiah Pendidikan Dan Pembelajaran, 5(2), 343. https://doi.org/10.23887/jipp.v5i2.36424.

Suja, I. W. (2017). Integrasi Kearifan Lokal Ke Dalam Kurikulum Ilmu Alamiah Dasar. Jurnal Matematika, Sains, Dan Pembelajarannya, 11(1), 77-93.

Sutajaya, I. M. (2020). Mendidik Masyarakat Melalui Konsep Tri Datu untuk Memertahankan Sikap Kewirausahaan Saat Pandemi COVID 19. Webminar Nasional 2020 "Pengembangan Kompetensi Pendidik Mengimplementasikan Program Merdeka Belajar", 78-88.

Syakur, A. (2021). Local wisdom for civil religious harmony in indonesia: An ethnographic investigation on mbah moni's grave ritual in babatan village, wiyung sub-district, surabaya city, Jawa Timur Province. Kasetsart Journal of Social Sciences, 42(3), 674-681. https://doi.org/10.34044/j.kjss.2021.42.3.32.

Torre, D. La, Liuzzi, D., \& Marsiglio, S. (2021). Transboundary pollution externalities: Think globally, act $\begin{array}{llll}\text { locally? Journal of Mathematical Economics, } & \text { 96(xxxx), } 102511 .\end{array}$ https://doi.org/10.1016/j.jmateco.2021.102511.

Voeks, R.S., J. R. S. (2018). Ethnoecology and Medicinal Plants of the Highland Maya. Springer Nature Switzerland AG.

Watanabe, Y. (2018). Think Globally, Act Locally. UNDP. 